\title{
Assess the Effects of Sucrose on Post-Anoxic Denitrification through Lab-Scaled Sequence Batch Reactors (SBRs)
}

\author{
Duc Anh Phung ${ }^{1}$ and Sy Chi Phung ${ }^{2}$ \\ 1. Faculty of Engineering and Information Technology, University of Technology Sydney, Sydney 2007, Australia \\ 2. Institute of Environmental Sciences, Nguyen Tat Thanh University, Ho Chi Minh City 84.8, Vietnam
}

\begin{abstract}
The aim of this study was to assess the impact of industrial-grade sucrose as external carbon source on post-anoxic denitrification. This was done through the use of lab-scaled Sequencing Batch Reactors (SBRs) modelling after a standard post-anoxic Waste Water Treatment Plant (WWTP). Each reactor holds an effective volume of approximately 4 L, with the decant volume of 2 L per cycle, a Hydraulic Retention Time (HRT) of 8 hours, Sludge Retention Time (SRT) of about $11.5 \pm 0.5$ days. The experiments showed that adding industrial-grade sucrose into the post-anoxic zone has a very significant improvement where the nitrate removal rate increased from $10 \%$ to $68 \%$. The experiment also verifies that most of the Specific Denitrification Rate (SDNR) calculated from the lab-scaled SBRs lie within the range of earlier study (2.29-2.85 $\left.\mathrm{mgNO}_{3}{ }^{-} / \mathrm{gMLVSS} / \mathrm{h}\right)$, and verified the results of both this experiment and the SDNR batch tests in previous study.
\end{abstract}

Key words: Sucrose, post-anoxic, denitrification, external carbon source, SBRs.

\section{Introduction}

The availability of readily biodegradable organic carbon is one of the key elements for complete denitrification, but it is also often the limiting substrate in this process [1-3]. This is because the denitrification usually happens after the nitrification process, where the more readily biodegradable organic carbon can be easily consumed. Adding an external carbon source into post-anoxic or pre-anoxic zone to boost denitrification hence could be a favorable solution. Because, it's easy to implement, it requires little modifications of an existing Wastewater Treatment Plant (WWTP) and can meet both the short term and long term treatment standard.

There have been many studies on the viability of different carbon sources to enhance denitrification. Generally, methanol is the most used and well-documented carbon source [4], and was

Corresponding author: Sy Chi Phung, associate professor, main research field: environmental science and technology. recommended by the US EPA. However, for large WWTPs, the cost for methanol can significantly increase the operating costs, not counting the fact that methanol is a valuable resource. Hence finding an alternative cost-effective external carbon substance is amongst the priorities of the wastewater treatment industry for the past two decades [5]. There have been many researches on materials which are rich in carbon, such as dairy industrial wastewater [6], corn starch [7], reject water [8], syrup from distillery waste product [1] food industries [6, 7, 9]. Many of these wastes or by-products were found to provide effective denitrification.

This experiment would look at industrial-grade sucrose, a by-product from sugar refining process, as a potential external carbon sources. Sucrose was chosen mainly due to its availability locally as a by-product rich in carbon, but also because it relates to a future experiment.

Another goal of this experiment is to verify the results from earlier SDNR tests, also on sucrose. This 
would be done by comparing the calculated denitrification rate of sucrose using the laboratory SBR system, with the denitrification rate of sucrose using a standard SDNR set-up in previous study.

\section{Material and Methods}

\subsection{Chemicals and Inoculums}

The sucrose used in this experiment is a by-product of sugar-refining industrial process from a sugar company. It's a very thick liquid with a light opaque yellow in color and fairly stable characteristic. It has an average COD constant of $1,125 \mathrm{mg} / \mathrm{g}$ despite storing in room temperature for months (theoretical COD for sucrose is $1,123 \mathrm{mg} / \mathrm{g}$ ). This sucrose solution would be diluted before being added into the batch experiments.

The lab-scaled SBR used synthetic wastewater consists of commercial beef extract as main organic carbon and organic nitrogen source. The nutrient and trace metal solutions for this synthetic wastewater were based on $\mathrm{Hu}$, et al. [10] consisting of $10 \mathrm{mg}$ $\mathrm{CaCl}_{2} / \mathrm{L}, 18 \mathrm{mg} \mathrm{K}{ }_{2} \mathrm{HPO}_{4} / \mathrm{L}, 11 \mathrm{mg} \mathrm{KH}_{2} \mathrm{PO}_{4} / \mathrm{L}, 10 \mathrm{mg}$ $\mathrm{MgSO}_{4} / \mathrm{L}, 0.15 \mathrm{mg} \mathrm{CoCl}_{2} / \mathrm{L}, 0.03 \mathrm{mg} \mathrm{CuSO}_{4} / \mathrm{L}, 10$ $\mathrm{mg} \mathrm{FeSO}_{4} / \mathrm{L}, 0.15 \mathrm{mg} \mathrm{H}_{3} \mathrm{BO}_{3} / \mathrm{L}, 0.18 \mathrm{mg} \mathrm{KI} / \mathrm{L}, 0.12$ $\mathrm{mg} \mathrm{MnCl}_{2} / \mathrm{L}, 0.06 \mathrm{mg} \mathrm{NaMoO}_{4} / \mathrm{L}$ and $0.12 \mathrm{mg}$ $\mathrm{ZnSO}_{4} / \mathrm{L}$. Most of the chemicals were supplied by Science Supply Australia.

\subsection{Denitrifying Biomass}

The SBRs were seeded with the raw sludge, rich in denitrifying biomass from Sunburry WWTP. The sludge was collected from the pre-anoxic zone, transported in ice box to the lab where it was sieved to remove any large particles before being fed into the
SBRs. The sludge was then operated under SBR cycle for at least 3-5 weeks before any experiments can be carried out with it. For this study, the SBR had been running for 6 months previous to the start of this experiment.

For the two tested SBRs to acclimate with sucrose, sucrose solution with COD concentrations of 150-170 $\mathrm{mg} / \mathrm{L}$ was added into the influent tank for 3 weeks previous to the start of the experiment

\subsection{Analytical Method}

COD, TN, Ammonia, Nitrate and Volatile Fatty Acid were analysed using $\mathrm{HACH}$ standard methods for the DR 5000 (Methods 8000, 10072, 10031, 10020 and 8196 respectively). $\mathrm{pH}$ and DO were tested by using the Mettler Toledo S20 Seveneasy pH meter and YSI 5100 dissolved oxygen meter.

Due to the soluble synthetic wastewater, the Mixed Liquor Volatile Suspended Solid (MLVSS) of all SBR reactors were found (using SPSS program) to be insignificantly different to the Mixed Liquor Suspended Solid (MLSS). Hence, these two values are interchanged in this experiment.

The MLSS was measured the same way with Total Solids, where $100 \mathrm{~mL}$ of sample were dried overnight in 105 degrees oven.

\subsection{Experimental Set-up}

The measured characteristics of the synthetic wastewater used for the SBR experiment is summarised in Table 1.

The concentration of nutrient and trace metal solutions is theoretically the same with the figures mentioned in section 2.1 .

Table 1 Synthetic wastewater characteristics.

\begin{tabular}{lll}
\hline No & Parameters & Characteristics \\
\hline 1 & Influent rate & $2 \mathrm{~L}$ per cycle $(6 \mathrm{~L}$ per day) \\
2 & $\mathrm{TN}$ & $55.6 \pm 1.4 \mathrm{mg} / \mathrm{L}$ \\
3 & $\mathrm{COD}$ & $456.8 \pm 26.5 \mathrm{mg} / \mathrm{L}$ \\
4 & $\mathrm{PO}_{4}$ & $17.25 \mathrm{mg} / \mathrm{L}$ \\
5 & $\mathrm{PO}_{4}-\mathrm{P}$ & $5.63 \mathrm{mg} / \mathrm{L}$ \\
6 & Temperature & $20.0-26.5^{\circ} \mathrm{C}$ \\
\hline
\end{tabular}




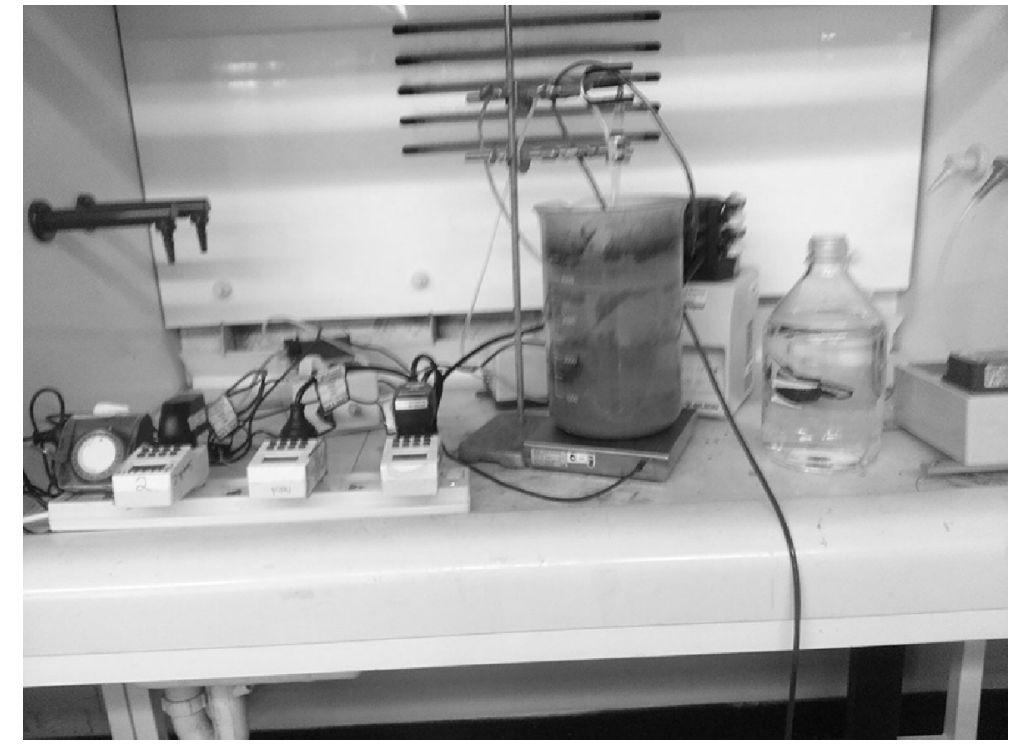

Fig. 1 A SBR used in this experiment.

Other than the obvious difference in scale, the main difference of the SBRs comparing to the standard wastewater treatment plants, is its time-dependency nature (in oppose to space dependency). This means: instead of separate anoxic, aerobic and clarifier tanks like standard WWTPs, all process of the SBRs happen inside the same reactor. This set-up provides a much more consistent Hydraulic Retention Time (HRT) and Sludge Retention Time (SRT) and grants a great advantage in monitoring the nitrification and denitrification process separately. For this specific experiment, the SBRs set-up also allows the direct calculation of SDNR at any certain point which will not possible in standard WWTP.

There are four SBRs which have been used in this experiment, the picture of one of the SBR system is in Fig. 1.

The SBRs have 3 continuous cycles a day, 7 days a week. One cycle of the SBR used in this experiment is 8 hours, consisting of 0.5 hours of unmixed feeding, 4 hours of aeration, 2 hours of anoxic mixing, 1 hour of settling and 25 minutes of decanting. The 5 minutes' gap at the end of the cycle is to prevent issues relating to timing devices error, where feeding and decanting happen in the same time leading to the loss of sludge or influent.
Overall the SBRs set-up follows a standard post-anoxic denitrification system. In addition, due to no aeration was done during the feeding period, the feeding period was also acted as a pre-denitrification zone that remove almost all of nitrate from previous cycle. That process is necessary as it prevent accumulation of nitrate inside of the system, something a real post-anoxic treatment system also doesn't have to face.

Each reactor holds an effective volume of approximately $4 \mathrm{~L}$, with the decant volume of $50 \%$ or $2 \mathrm{~L}$ per cycle. During aerobic phase, the DO level is kept to be higher than $3 \mathrm{mg} / \mathrm{L}$ to ensure the maximum nitrification to occur. The Hydraulic Retention Time (HRT) is 16 hours. The Sludge Retention Time (SRT) was selected to be $11.5 \pm 0.5$ days based on literature $[11,12]$, providing an MLVSS of 2,200-2,600 mg/L.

The SBRs had been running for more than 6 months previous to the start of the experiment, but the data collected for this specific experiment is only for 7 weeks. For the first 3.5 weeks, no external carbon source was used. During the next 3.5 weeks, sucrose solution was pumped into the post-anoxic cycle of the test SBRs, to increase the rbCOD of the reactors by $150-170 \mathrm{mg} / \mathrm{L}$. 
The reason 7 weeks were chosen is because each 3.5 weeks period represented roughly 2 SRTs of the SBRs (22-24 days).

The SBRs performance was monitored twice a week for $\mathrm{NO}_{3}{ }^{-}, \mathrm{NH}_{4}{ }^{+}, \mathrm{TN}, \mathrm{COD}, \mathrm{pH}, \mathrm{DO}$ and the effect of sucrose on the system denitrification was assessed.

\section{Results and Discussion}

\subsection{Effect of Sucrose on the SBR Denitrification}

The recorded nitrate results of the 4 SBRs are represented in Figs. 2 and 3. The Reactors A and C are duplicates as control reactors. The Reactors B and D are duplicates as tested reactors where sucrose were only added in after the 25 th day.

The reactor label (A-D) was numbered based on their location in the lab, so the tested and control reactors were mixed up ( $\mathrm{A}$ with $\mathrm{C}, \mathrm{B}$ with $\mathrm{D}$ ) to make sure that their location (and associated variables like distance to the feed tanks, or air flow...) would not have significant effect on the test.

As showed in the graphs, there was very limited denitrification during the anoxic period in all reactors

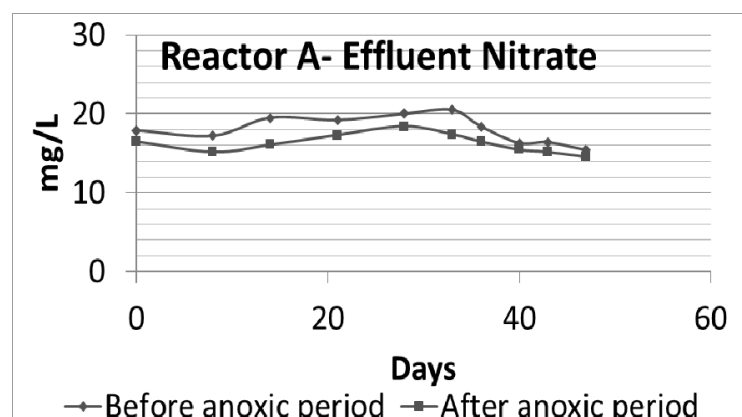

$\rightarrow$ Before anoxic period $\rightarrow$-After anoxic period

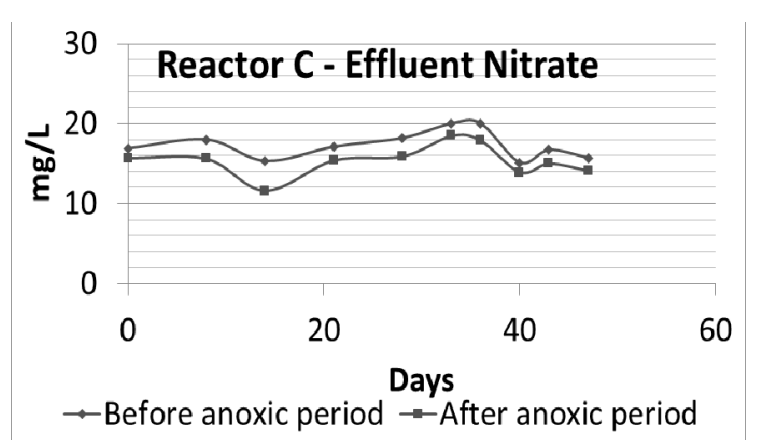

Fig. 2 Nitrate concentration before and after anoxic zone in Control Reactor (A and C).

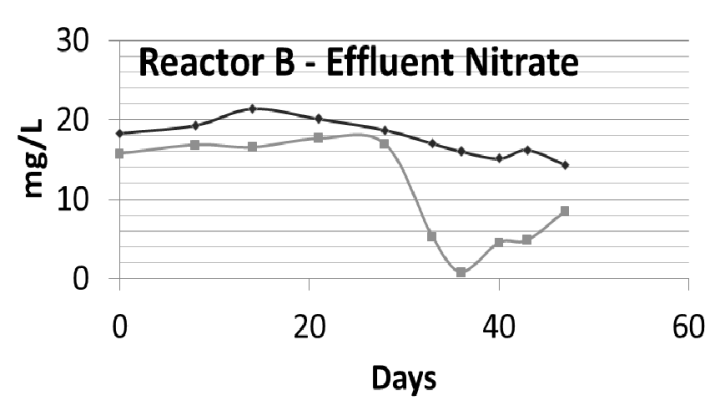

$\rightarrow-$ Before anoxic period - -After anoxic period

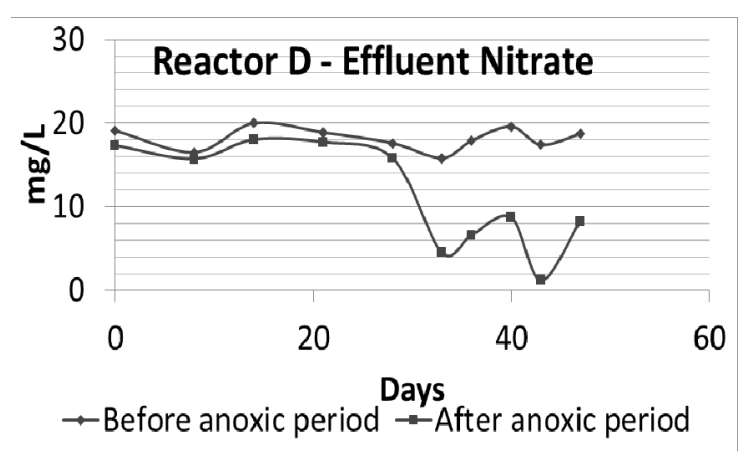

Fig. 3 Nitrate concentration before and after anoxic zone in Tested Reactors (B and D).

when sucrose was not added in. This was actually expected as the SBRs faced the same problem with the most of post-denitrification wastewater treatment system: the readily biodegradable carbon in the influent was used up during the aerobic zone (stationed previous to the anoxic zone). This can be seen by the average COD of all four SBR reactors during the previous 6 months before operation in Table 2 .

It has to be taken into account that the synthetic wastewater soluble COD is $456.8 \pm 26.5 \mathrm{mg} / \mathrm{L}$, and the decant rate is $50 \%$. This means the initial soluble COD of each reactor at the beginning of each cycle theoretically always is at least $228.4 \pm 13.2 \mathrm{mg} / \mathrm{L}$. The actual figure can't be measured however, as the COD of synthetic wastewater is quickly consumed, even before it is well mixed with the reactor.

Note in Table 2 how the COD after anoxic period of each reactor was almost identical to the COD before anoxic period. This indicated that most of the COD remained before the anoxic zone was either very slowly degradable COD, or non-inorganic COD which 
Table 2 The measured COD of the SBRs.

\begin{tabular}{llll}
\hline No & Reactors & Before anoxic period $(\mathrm{mg} / \mathrm{L})^{*}$ & After anoxic period $(\mathrm{mg} / \mathrm{L})$ \\
\hline 1 & SBR A & $34.4 \pm 15.9$ & $33.9 \pm 12.9$ \\
2 & SBR B & $34.9 \pm 15.1$ & $35.5 \pm 14.0$ \\
3 & SBR C & $34.4 \pm 15.7$ & $34.4 \pm 17.1$ \\
4 & SBR D & $51.9 \pm 49.6$ & $52.5 \pm 56.7$ \\
\hline
\end{tabular}

Table 3 The measured $\mathrm{NO}_{3}$ of the SBRs.

\begin{tabular}{llrrrr}
\hline No & Nitrate concentration & SBR A & \multicolumn{1}{c}{ SBR B } & \multicolumn{1}{c}{ SBR C } & \multicolumn{1}{c}{ SBR D } \\
\hline 1 & Before anoxic period $(\mathrm{mg} / \mathrm{L})$ & $17.4 \pm 1.8$ & $15.7 \pm 0.9$ & $17.5 \pm 2.1$ & $17.9 \pm 1.3$ \\
2 & After anoxic period $(\mathrm{mg} / \mathrm{L})$ & $15.8 \pm 1.0$ & $4.8 \pm 2.4$ & $15.9 \pm 1.9$ & $5.8 \pm 2.7$ \\
3 & Nitrate removed $(\mathrm{mg} / \mathrm{L})$ & $1.6 \pm 0.9$ & $11.0 \pm 3.0$ & $1.6 \pm 0.3$ & $12.0 \pm 2.1$ \\
\hline
\end{tabular}

can't be utilised by denitrifiers. More discussion on this is in Section 3.2 of this paper.

The nitrate removal performance of the four SBRs can be summarised in Table 3 above. The results showed a very significant improvement in denitrification in tested reactors (B and $\mathrm{D})$ comparing to control reactors ( $\mathrm{A}$ and $\mathrm{C}$ ). The nitrate removal increased from $10 \%$ to $68 \%$ of total remained nitrate and reduces it down to way below the general worldwide standard of $10 \mathrm{mg} / \mathrm{L}$.

\subsection{SDNR Calculated from SBRs VS SDNR Batch Experiments}

Earlier SDNR batch tests with sucrose using real wastewater and sludge found that the SDNR of sucrose was 2.29-2.85 $\mathrm{mgNO}_{3}-/ \mathrm{gMLVSS} / \mathrm{h}$. The range is based on the $95 \%$ Confidence Interval $(\mathrm{CI})$, with adjusted $R^{\wedge} 2$ of 0.9573 .

The SDNR of each SBR also can be calculated based on the net drop in nitrate. More specifically the SDNR is the removed $\mathrm{NO}_{3}-\mathrm{N}$ concentration by $1 \mathrm{~g}$ of MLVSS biomass in 1 hour [13]. Or:

$$
S D N R=\frac{\Delta\left(\mathrm{NO}_{3} \cdot \mathrm{N}+0.6 \mathrm{NO}_{2} \cdot N\right)}{M L V S S \times V \times t}
$$

where $\mathrm{V}$ : volume of the reactor $(4 \mathrm{~L}), \mathrm{t}$ : reaction time (2 hours), MLVSS: mixed liquor volatile suspended solid, measured at the time. Note $\mathrm{NO}_{2}$ also was measured at first, but the concentration was showed to be insignificant due to its instability. Hence it was omitted from this study.

The denitrification rate for every 3-4 days of each SBR hence can be calculated using the equation and was graphed in Fig. 4.

The results firstly confirmed that there was a near depletion of organic soluble COD in the post-anoxic zone (Table 2). That's why the denitrification rates of the control reactors (and of tested reactors before adding sucrose) fall close to or just slightly higher than the theoretically endogenous SDNR rate (0.3-0.4 $\mathrm{mgNO}_{3}{ }^{-} / \mathrm{gMLVSS} / \mathrm{h}$ ).

But more important, other than a few exception, most of the SDNR calculated from this SBRs experiment fell into the range of 2.29-2.85 $\mathrm{mgNO}_{3}{ }^{-} / \mathrm{gMLVSS} \mathrm{h}$ gotten from previous study. This hence could verify the validity of both the SBR results presented in this experiment and of previous SDNR batch tests.

MLVSS and $\mathrm{NH}_{4}$ were also measured during the course of the experiment but did not show any significant change.

\section{Conclusion}

The major findings from these experiments can be summarised as below:

Adding sucrose into the post-anoxic zone showed a very significant improvement in denitrification. The nitrate removal efficiency during post-anoxic zone increased from $10 \%$ in the control SBRs to $68 \%$ of tested SBRs. This reduced nitrate concentration of the 


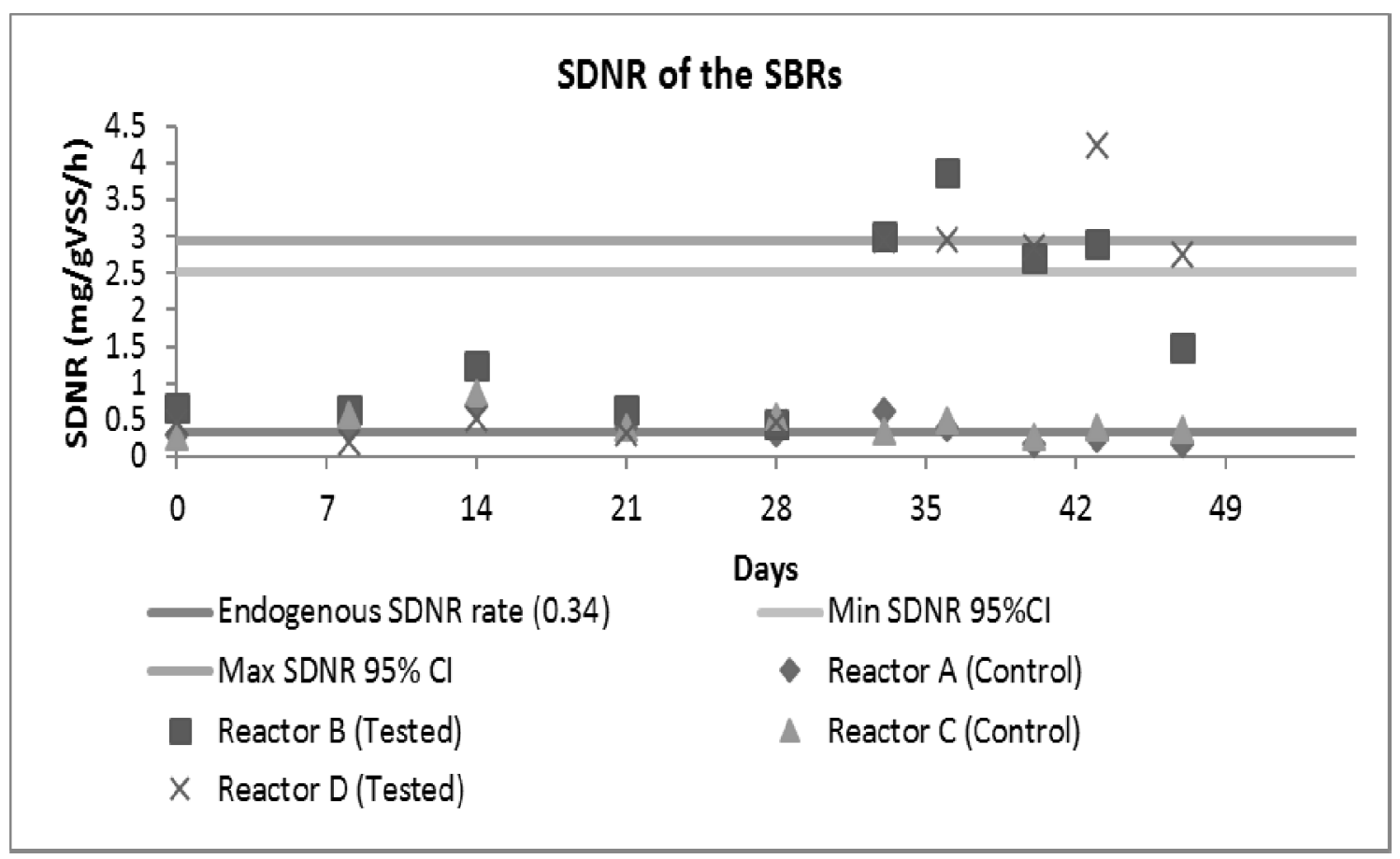

Fig. 4 SDNR of the four SBR reactors.

Note: the range of $95 \% \mathrm{CI}$ of the SDNR are based on SDNR batch tests from earlier study.

effluent from $15.8 \pm 1.0 \mathrm{mg} / \mathrm{L}$ and $15.9 \pm 1.9 \mathrm{mg} / \mathrm{L}$ in control reactors to $4.8 \pm 2.4 \mathrm{mg} / \mathrm{L}$ and $5.8 \pm 2.7 \mathrm{mg} / \mathrm{L}$ of tested reactors respectively.

Without adding an external carbon sources, post-anoxic zone will have very limited organic soluble COD to carry out denitrification. As almost entire remained COD is either non-soluble or inorganic. Denitrification during this time will have to depend mostly on the endogenous denitrification rate of only 0.3-0.4 $\mathrm{mgNO}_{3}{ }^{-} / \mathrm{gMLVSS} / \mathrm{h}$.

Most of the denitrification rates calculated from the lab-scaled SBRs lie within the range of earlier SDNR batch test (2.29-2.85 $\left.\mathrm{mgNO}_{3}{ }^{-} / \mathrm{gMLVSS} / \mathrm{h}\right)$. This verified the results of both previous SDNR batch tests and of this SBRs experiment and actually is quite significant. Especially when consider the SDNR range from SDNR batch tests were using sludges taken from a real WWTP, and gotten based on the $95 \%$ CI value analysed by R Statistics. While the SBRs have already acclimated in the lab for 6 months, and the SDNR was measured by directly divided the nitrate removal over time.

\section{References}

[1] Makinia, J., Czerwionka, K., Oleszkiewicz, J., Kulbat, E., and Fudala-Ksiazek, S. 2011. "A Distillery By-product as an External Carbon Source for Enhancing Denitrification in Mainstream and Sidestream Treatment Processes." Water Science and Technology 64: 2072-2079.

[2] Meyer, R. L., Zeng, R. J., Giugliano, V., and Blackall, L. L. 2005. "Challenges for Simultaneous Nitrification, Denitrification, and Phosphorus Removal in Microbial Aggregates: Mass Transfer Limitation and Nitrous Oxide Production." FEMS Microbiology Ecology 52 (3): 329-338.

[3] Puig, S., Coma, M., van Loosdrecht, M. C. M., Colprim, J., and Balaguer, M. D. 2007. "Biological Nutrient Removal in a Sequencing Batch Reactor Using Ethanol as Carbon Source." Journal of Chemical Technology and Biotechnology 82 (10): 898-904.

[4] Swinarski, M., Makinia, J., Czerwionka, K., and Chrzanowska, M. 2009. "Industrial Wastewater as an External Carbon Source for Optimization of Nitrogen Removal at the "Wschod" WWTP in Gdansk (Poland)." Water Science and Technology 59 (1): 57-64.

[5] Oleszkiewicz, J. A., Kalinowska, E., Dold, P., Barnard, J. L., Bieniowski, M., Ferenc, Z., et al. 2004. "Feasibility Studies and Pre-design Simulation of Warsaw'new Wastewater Treatment Plant. " Environment Technololgy 25 (12): 1405-1411. 
[6] Sage, M., Daufin, G., and Gésan-Guiziou, G. 2006. "Denitrification Potential and Rates of Complex Carbon Source from Dairy Effluents in Activated Sludge System." Water Research 40 (14): 2747-2755.

[7] Cappai, G. C., and Onnis, A. 2004. "Use of Industrial Wastewaters for the Optimization and Control of Nitrogen Removal Processes." Water Science Technology 50 (6): 17-24.

[8] Lee, N. M., and Welander, T. 1996. "The Effect of Different Carbon Sources on Respiratory Denitrification in Biological Wastewater Treatment." Journal of Fermentation and Bioengineering 82 (3): 277-285.

[9] Quan, Z. X., Jin, Y. S., Yin, C. R., Lee, J. J., and Lee, S. T. 2005. "Hydrolyzed Molasses as an External Carbon Source in Biological Nitrogen Removal." Bioresource Technology 96 (15): 1690-1695.

[10] Hu, Z., Zhang, J., Li, S. P., Xie, H. J., Wang, J. H., Zhang,
T. T., et al. 2010. "Effect of Aeration Rate on the Emission of $\mathrm{N} 2 \mathrm{O}$ in Anoxic-aerobic Sequencing Batch Reactors (A/O SBRs)." Journal of Bioscience and Bioengineering 109 (5): 487-491.

[11] Kargi, F., and Uygur, A. 2004. "Hydraulic Residence Time Effects in Biological Nutrient Removal Using Five-step Sequencing Batch Reactor." Enzyme and Microbial Technology 35 (2): 167-172.

[12] Obaja, D., Macé, S., Costa, J., Sans, C., and Mata-Alvarez, J. 2003. "Nitrification, Denitrification and Biological Phosphorus Removal in Piggery Wastewater Using a Sequencing Batch Reactor." Bioresource Technology 87 (1): 103-111.

[13] Metcalf, E., Eddy, H. P., and Tchobanoglous, G. 2003. Wastewater Engineering: Treatment, Disposal, and Reuse/Metcalf \& Eddy, Inc, 4th ed. New York: McGraw-Hill. 